\title{
Mechanical analysis of insertion problems and pain during colonoscopy: Why highly skill-dependent colonoscopy routines are necessary in the first place... and how they may be avoided
}

\author{
Arjo J Loeve MSc PhD ${ }^{1}$, Paul Fockens MD PhD², Paul Breedveld MSc PhD ${ }^{1}$
}

\begin{abstract}
AJ Loeve, P Fockens, P Breedveld. Mechanical analysis of insertion problems and pain during colonoscopy: Why highly skill-dependent colonoscopy routines are necessary in the first place... and how they may be avoided. Can J Gastroenterol 2013;27(5):293-302.
\end{abstract}

BACKGROUND: Colonoscopy requires highly skill-dependent manoeuvres that demand a significant amount of training, and can cause considerable discomfort to patients, which increases the use of sedatives. Understanding the underlying fundamental mechanics behind insertion difficulties and pain during colonoscopy may help to simplify colonoscopy and reduce the required extent of training and reliance on sedatives.

METHODS: A literature search, anatomical studies, models of the colon and colonoscope, and bench tests were used to qualitatively analyze the fundamental mechanical causes of insertion difficulties and pain. A categorized review resulted in an overview of potential alternatives to current colonoscopes.

RESULTS: To advance a colonoscope through the colon, the colon wall, ligaments and peritoneum must be stretched, thus creating tension in the colon wall, which resists further wall deformation. This resistance forces the colonoscope to bend and follow the curves of the colon. The deformations that cause insertion difficulties and pain (necessitating the use of complex conventional manoeuvres) are the stretching of ligaments, and stretching of colon wall in the transverse and longitudinal directions, and the peritoneum.

CONCLUSIONS: Four fundamental mechanical solutions to prevent these deformations were extracted from the analysis. The current results may help in the development of new colonoscopy devices that reduce - or eliminate - the necessity of using highly skilldependent manoeuvres, facilitate training and reduce the use of sedatives.

Key Words: Colonoscopy; Endoscopy; Training

$\mathrm{H}$ ighly advanced colonoscopes ('scope[s]') are used to screen the human colon for diseases and abnormalities, and also for treatment. A scope is an endoscope with a $1.2 \mathrm{~m}$ to $1.6 \mathrm{~m}$ long flexible but torsionally stiff shaft. Its distal end ('tip') can be bent in four directions by twisting control wheels on a grip at the proximal end of the scope. A digital camera, light supply fibres and channels for instruments, air and water are embodied in the instrument. The scope is inserted into the anus and pushed into the colon up to the cecum or terminal ileum, while bending the tip to negotiate around colonic bends $(1,2)$.

The functionally necessary flexibility and length of the scope shaft and the floppy nature of the colon and its attachments hamper, and may prohibit, reaching the cecum and visualizing the entire colon (success rates for experienced endoscopists generally average between
L'analyse mécanique des problèmes d'insertion et de la douleur pendant la coloscopie : pourquoi des modalités de coloscopie hautement tributaires des habiletés sontelles nécessaires... et comment les éviter

HISTORIQUE : La coloscopie exige des manœuvres hautement tributaires des habiletés qui exigent une formation importante et peuvent provoquer des malaises considérables chez les patients, lesquels accroissent le recours aux sédatifs. Si on comprend la mécanique fondamentale sous-jacente aux problèmes d'insertion et de douleur pendant la coloscopie, on pourra peut-être simplifier l'intervention et réduire la durée de formation et l'utilisation des sédatifs.

MÉTHODOLOGIE : Les chercheurs ont effectué une recherche dans les publications, des études anatomiques, des modèles du côlon et du coloscope et des bancs d'essai pour procéder à l'analyse quantitative des causes mécaniques fondamentales des problèmes d'insertion et de douleur. Grâce à une analyse par catégories, ils ont pu avoir un aperçu des possibilités pour remplacer les coloscopes actuels.

RÉSULTATS : Pour faire progresser un coloscope dans le côlon, il faut étirer la paroi du côlon, les ligaments et le péritoine, ce qui crée une tension dans la paroi du côlon qui résiste à une telle déformation. En raison de cette résistance, le coloscope plie et suit les courbes du côlon. Les déformations responsables des difficultés d'insertion et de la douleur (exigeant le recours à des manœuvres classiques complexes) sont l'étirement des ligaments et du péritoine, de même que l'étirement de la paroi du côlon dans les directions transversales et longitudinales.

CONCLUSIONS : Les chercheurs ont extrait de l'analyse quatre solutions mécaniques fondamentales pour prévenir ces déformations. Les résultats pourraient contribuer à l'élaboration de nouveaux dispositifs de coloscopie qui réduisent ou éliminent la nécessité de recourir à des manœuvres hautement dépendantes des habiletés, facilitent la formation et réduisent l'utilisation de sédatifs.

$80 \%$ and $99 \%$, with some averages $<80 \%)(3-9)$. This results in colonoscopy being a time-consuming procedure and one that is difficult to master $(4-8,10)$. Furthermore, the extensive training in practice that is required to master gastrointestinal endoscopy procedures has a negative effect on endoscopy case throughput and cost (11). The actions required to perform a full colonoscopy can also be painful for the patient. Sedation is often used to prevent pain, although it increases the risk of complications and lowers patient satisfaction $(12,13)$.

Many attempts to reduce patient discomfort have been made, ranging from using hypnosis or music, to using thinner scopes or using water to expand the colon (14). Current colonoscopy manuals and the literature extensively describe the conventional scope manoeuvres that can be used to prevent or solve insertion problems (1,2,15-17). However,

\footnotetext{
${ }^{1}$ Department of BioMechanical Engineering, Faculty $3 \mathrm{mE}$ - Mechanical, Maritime and Materials Engineering, Delft University of Technology, Delft;

${ }^{2}$ Department of Gastroenterology and Hepatology, Academic Medical Center, University of Amsterdam, Amsterdam, The Netherlands

Correspondence: Dr Arjo J Loeve, Department of BioMechanical Engineering, Faculty $3 \mathrm{mE}$ - Mechanical, Maritime and Materials Engineering, Delft

University of Technology, Mekelweg 2, 2628 CD, Delft, The Netherlands. Telephone 31-0-15-2782977, e-mail a.j.loeve@tudelft.nl

Received for publication October 4, 2012. Accepted November 5, 2012
} 


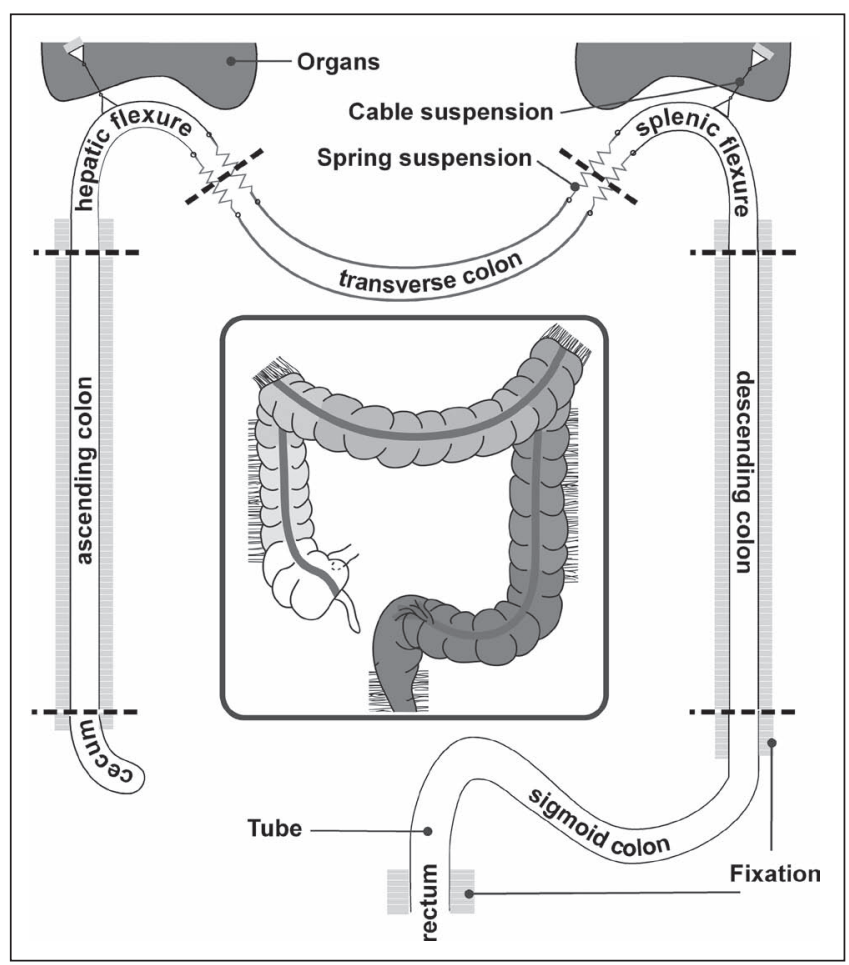

Figure 1) Average colon anatomy (centre frame) and modelled colon (around centre frame)

they do so from an experience-based perspective and not in terms of fundamental mechanical causes and solutions. Creating early awareness of the mechanical and kinetic behaviour of the colonoscope and the patient's anatomy may help to improve endoscopist performance (18). This may work even better when combined with well-structured training programs that carefully make use of trainees' self-assessment and structured practice such as those described by Mohammed et al (19). Understanding the mechanisms that cause conventional scope manoeuvres and sedation to be required may help to develop solutions that would make both highly skill-dependent techniques and sedation less necessary (or unnecessary). This would enable endoscopists to undergo less costly and more rapid training; reduce procedure times, complications and the use of sedatives; and increase colonoscopy success rates. Such improvements would, in turn, make colonoscopy more suitable for broad-based screening.

The current article presents an analysis of the fundamental mechanical causes of insertion difficulties and pain during colonoscopy to gain understanding about why conventional scope manoeuvres and sedation are currently required. Taking this mechanical point of view is an attempt to fill the gaps in flexible endoscopy manuals and the literature. The results of the analysis will be used as hypotheses to design studies aimed at expanding the fundamental knowledge of insertion problems and pain, and to properly guide the design of new instruments for colonoscopy. Simple theoretical models of the colon and the scope were used to simplify the analysis. The final section of the present article contains a brief, categorized overview of alternatives to the current colonoscopes that are suggested in the scientific and patent literature.

\section{FUNDAMENTAL MECHANICAL CAUSES}

Generally, the key to a successful colonoscopy is to make and keep the sigmoid colon straight during and after the scope reaches the descending colon $(1,2,17,20-22)$. To do so, the sigmoid colon must first be passed, which can be difficult. Commonly, the most challenging areas for scope insertion are the S-shaped sigmoid colon, the $\mathrm{U}$-shaped splenic flexure, the wide U-shaped transverse colon and the U-shaped hepatic flexure $(1,2,15-17,23)$. Each anatomical part has its own characteristic shape, fixation, suspension and problem scenarios.

Although challenging situations in the transverse colon and right lateral colon differ in appearance and suggested solutions $(1,2,17,20$ 22), their fundamental mechanical causes, as well as the fundamental mechanisms that lead to solutions, are similar to those in the sigmoid colon. Therefore, full scope insertion was analyzed, but only the trajectory up to the splenic flexure is discussed in detail in the present article. The results of the analysis are illustrated using some of the often occurring loops that are best known to endoscopists.

\section{Model derivation}

Conventional scope manoeuvres are used in all types of subjects. Therefore, an average healthy anatomy is used to model the colon. The centre of Figure 1 depicts an anatomical scheme of a human colon. The outer area of Figure 1 shows the colon modelled as a very flexible, elastic tube. Movement and deformation of the colon are limited by three factors: stiffness of the colon wall; stiffness of the abdominal wall and the organs surrounding the colon; and the suspending 'ligaments' of the colon.

Some simplifications and assumptions were made to prevent the model of the colon from becoming unnecessarily complex. The colon wall is modelled as a smooth tube because wrinkles (as found along the entire length of the colon) have little influence on the bending behavior of a lax tube. The small bowel acts as a viscous mass that limits the movement and deformations of the colon in all directions and is, therefore, modelled by increasing the deformation resistance of the colon. Abdominal pressure is omitted from the model because abdominal pressure differs little from atmospheric pressure (24-26). Movements and deformations of the colon are assumed to remain inside the abdomen. Therefore, the abdominal wall is omitted from the model. Friction between the colon and the scope is excluded because it is significantly reduced by the slippery mucosa present inside the colon.

The rectum lies fixed on the pelvic bone and is, therefore, modelled as a fixed part of the sigmoid colon. The sigmoid colon lies as an almost free S-shape between the rectum and the descending colon. The descending colon, constrained over its entire length by tight ligament attachments, is modelled as being entirely fixed. The splenic flexure, which is suspended by a ligament that can bend freely but can barely stretch, is modelled as being suspended by a cable (which can also bend freely and barely stretch). Organs surrounding the colon (spleen, liver) prevent the splenic flexure from moving far upward. The peritoneum is very thin and folded, and is assumed to only slightly influence the behaviour of the sigmoid and transverse colon. It is modelled as an increased deformation resistance of the colon.

The transverse colon hangs between the splenic and hepatic flexures. The connections between the transverse colon and both flexures are parts of - and thus equally as elastic - the colon wall and, are therefore, modelled as springs. The hepatic flexure and the ascending colon are modelled as a mirrored copy of the splenic flexure and the descending colon. The cecum hangs freely on the ascending colon.

During colonoscopy, the patient's position is occasionally altered to let the colon drop into a better configuration or enable gravity help propel the endoscope $(1,2)$. The effects of gravity are omitted from the model because they do not alter the fundamental behaviour of the colon or the scope. The same applies to colon inflation and deflation techniques. The scope's stiffness is assumed to be similar to that of well-developed modern scopes (ie, optimized to be pushed through the colon) and to have ideal spring-like properties.

\section{Insertion difficulties}

\section{ANALYSIS}

Flat loop: To determine why these manoeuvres are indispensable to conventional colonoscopy, the analysis first views colonoscopy without highly skill-dependent scope manoeuvres. Therefore, in the analysis, 


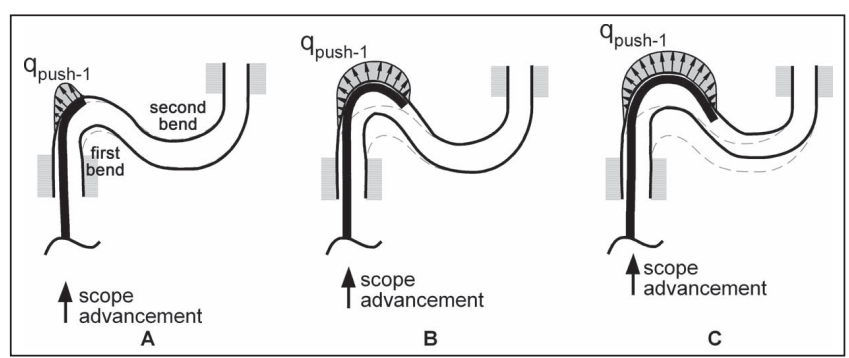

Figure 2) The three stages of scope advancement through the first bend of the sigmoid colon and the normal forces (qpush-1) that are exerted by the scope shaft on the colon wall. A First stage: bend enlargement is mainly caused by moving the colon. B Second stage: bend enlargement is mainly caused by stretching the colon. C Third stage: equilibrium

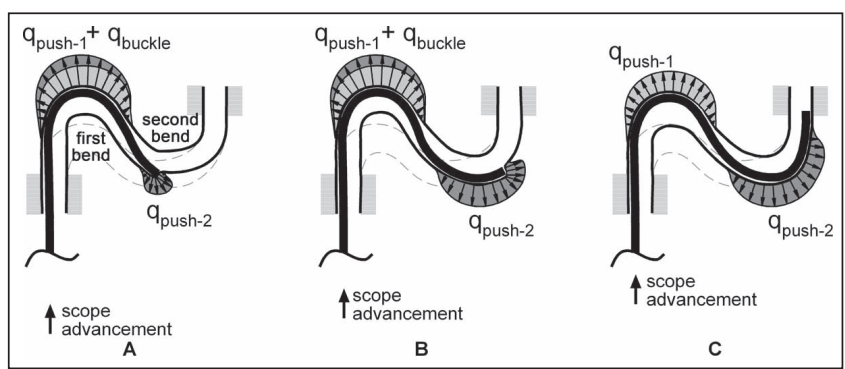

Figure 3) The three stages of scope advancement through the second bend of the sigmoid colon. A First stage: the scope tip enters the second bend and deforms the colon wall, thereby exerting normal forces $\left(q_{\text {push-2 }}\right)$ on the colon wall. Reaction forces on the front side of the tip push back on the scope, adding buckling forces $\left(q_{\text {buckle }}\right)$ in the first bend. B Second stage: the scope tip advances, the forces grow and the bends continue to stretch. C Third stage: the tip has passed the second bend. The tip lies freely in the colon, causing $q_{\text {buckle }}$ to disappear and allowing the first bend to recover from the stretching that was added due to buckling effects

the scope is advanced through the colon solely by pushing against the shaft and steering the tip.

When the scope is pushed into the first bend of the (modelled) sigmoid colon - by using only straightforward insertion without any special straightening or twisting manoeuvres - the scope tip will eventually contact the first bend in the outer curve. Figure 2A depicts a qualitative impression of the push force distribution $\left(\mathrm{q}_{\text {push-1 }}\right)$ on the colon wall during first contact between the scope and the colon. There are only normal forces (forces acting perpendicular to contact surfaces) and no tangential forces (forces acting along contact surfaces) because the presence of mucosa is assumed to eliminate all friction. During this first insertion stage, deformation stresses in the colon wall are small and the colon provides little resistance. This is because the colon wall is primarily being pushed away and the bend enlarges by drawing length from the second bend.

The stiffness of the scope resists bending in a spring-like manner. The further the scope shaft is bent, the more force is needed. Thus, during scope advancement, the magnitude of $\mathrm{q}_{\text {push-1 }}$ increases (Figure 2B). When the second bend has no more length to offer, the colon must stretch to enable further enlargement of the first bend. Meanwhile, deformation stresses in the colon wall grow due to the increasing stretching of the colon and these stresses begin to equal the push force and guide the scope along the bend.

In the third stage (Figure 2C), the tip has passed the first bend. The stresses in the colon wall and the push forces exerted by the scope on the colon wall are now in equilibrium. The bent length of the scope and the force required to bend it (the scope is assumed to behave similar to an ideal spring) is constant, and the scope follows the bend without further stretching the bend.

The scope tip can prod into the colon wall because the colon wall is 'floppy' (Figure 3A). If this happens, the tip applies push forces on

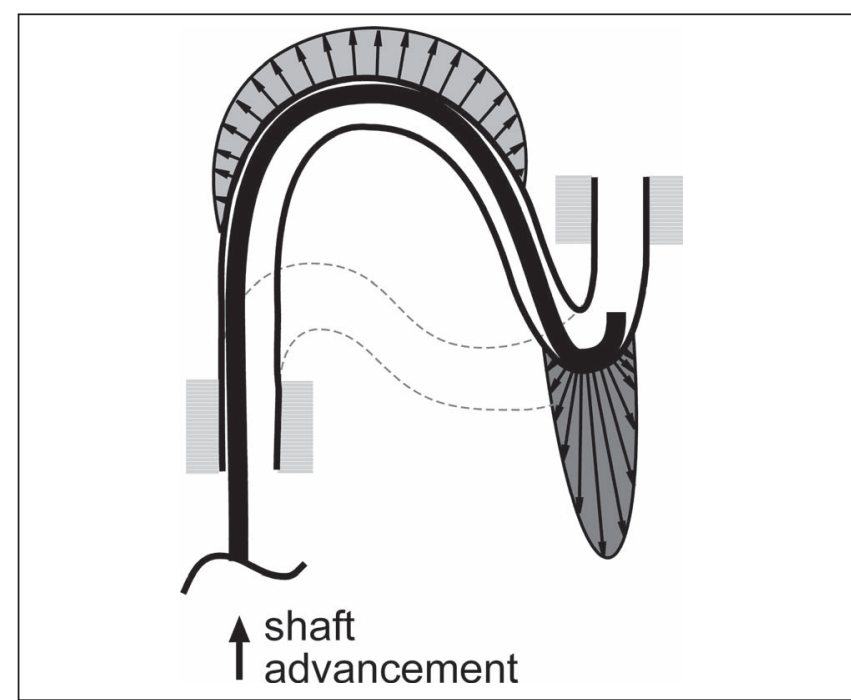

Figure 4) A flat loop with an acute second bend. Normal forces on the colon wall are indicated by small arrows

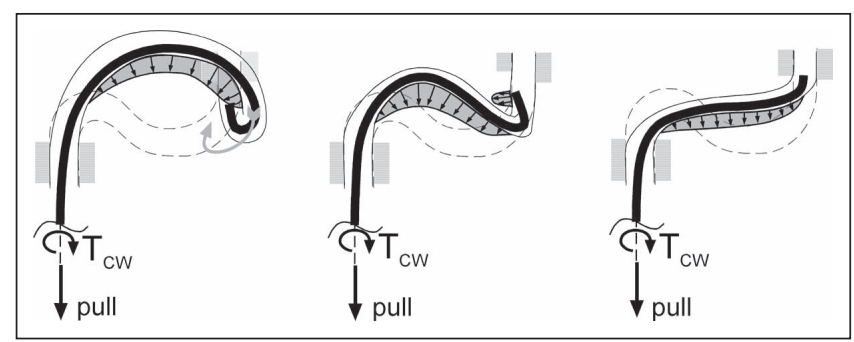

Figure 5) Straightening an N-loop. The relatively high stiffness of the scope shaft is used to lift and pull back the distal part of the scope and straighten the colon by applying twist $\left(\mathrm{T}_{\mathrm{CW}}\right)$ to the scope shaft and pulling it back

the colon wall with its frontal surface; hence, a reaction force acts against that surface and the scope shaft is pushed against from two sides. This can cause buckling of the scope shaft, which adds buckling forces $\left(q_{\text {buckle }}\right)$ to $q_{\text {push-1 }}$. During further advancement (Figure 3B), the total force on the second bend $\left(q_{\text {push-2 }}\right)$ increases together with the length of bent scope in that bend. When the tip has passed the second bend and no longer prods into the wall (Figure 3C), $\mathrm{q}_{\text {buckle }}$ disappears and the first bend recovers from the amount of stretching that was initially caused by the buckling of the scope shaft.

Flat loop with acute bend: In a very lax or very long sigmoid colon, the first bend can be enlarged considerably by drawing more length from and reducing the bending radius of the second bend (Figure 4) before the first bend provides sufficient resistance to guide the scope. In such a case, because the scope tip must bend very sharply to fit in the second bend, all forces in the second bend act on a single small area, which inhibits tip advancement and increases the risk of colon perforation $(1,2)$.

N-loop: Because the sigmoid colon is barely constrained in the direction perpendicular to the plane of the model, three-dimensional configurations are also possible. One example is the $\mathrm{N}$-shaped loop that occurs when the sigmoid colon partially moves out of its plane. This allows the first bend to move over the second (Figures 5 and 6). This loop resembles a flat loop with an acute bend in which the first bend is enlarged so much that it runs over the descending colon.

When an acute bend occurs somewhere in the trajectory, that bend's radius must be enlarged before advancement of the scope is possible $(1,2)$. Note that fully straightening a bend means making its radius of curvature infinitely large. Conventional colonoscopy routines aimed at enlarging acute bends use the same mechanisms that can cause difficult configurations. The relatively high stiffness of the 


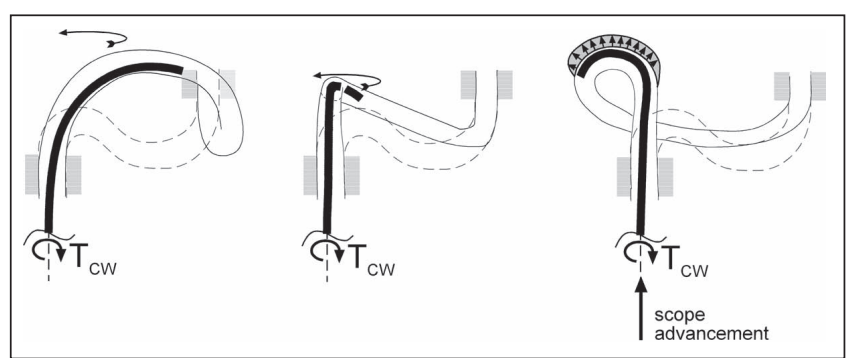

Figure 6) Transforming an N-loop into an $\alpha$-loop (far right) by pulling the scope back, out of the formed N-loop (far left), and using twist ( $\left.T_{C W}\right)$

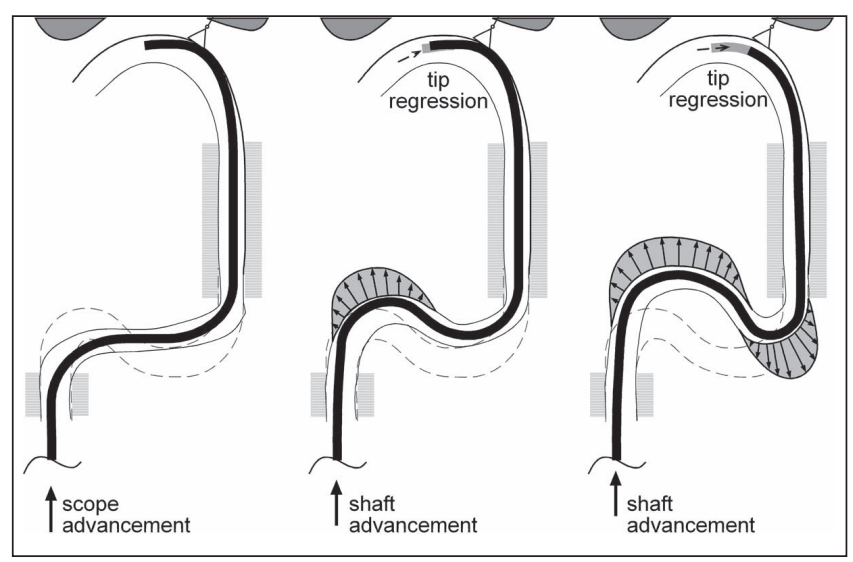

Figure 7) Starting recurrent looping. When loops in the sigmoid colon form, the tip can go backwards while the proximal shaft is pushed forward

scope shaft forces the floppy colon to move with the scope. An example of a routine that enlarges the acute bend in an N-loop is presented in Figure 5 (1,2).

$\boldsymbol{\alpha}$-loop: An $\alpha$-loop is a loop that runs from the rectum to the right lateral abdomen and back to the descending colon. This causes the (sigmoid) colon to assume a large bending radius, allowing easy passage of the scope because smaller forces are required to bend the scope into the shape of the loop. An $\alpha$-loop can be intentionally formed during scope insertion by using the scope to twist the sigmoid colon to the right lateral side of the abdomen or by transforming an $\mathrm{N}$-loop into an $\alpha$-shaped loop (Figure 6) (1,2).

Recurrent looping: A healthy descending colon is straight, relatively fixed and does not hinder scope insertion by itself. However, it is crucial to first straighten loops in the sigmoid colon before advancing through the descending colon. Otherwise, 'recurrent looping' can occur due to easier buckling of the shaft $(1,2)$. Furthermore, when the scope is bent sharply or in many loops, the forces that are applied to the proximal end of the shaft are not properly transferred to the tip, which deteriorates tip control due to friction inside the scope.

Figure 7 illustrates recurrent looping in its early stage. When trying to advance the scope through the splenic flexure, the scope can bend or buckle where it is not sufficiently straight or guided. The endoscopist has no visual of the behaviour of the scope shaft, which can further complicate scope insertion. For example, the endoscopist may reinitiate loop formation by trying to resolve suspected looping in the splenic flexure by twisting the shaft while loops are actually reforming in the sigmoid colon due to the very same manoeuvre.

From splenic flexure to cecum: The splenic flexure can be difficult to pass if it is acutely bent. The solution for further advancement is similar to other acute bends: enlarge the bend. This can be performed relatively easily because the proximal end of the splenic flexure is fairly unconstrained and can easily adapt its shape to the scope.

The transverse colon should be easily passed because it can move down while being constrained only by its length and flexures and, therefore, easily adapts its shape to the scope. The scope shaft exerts

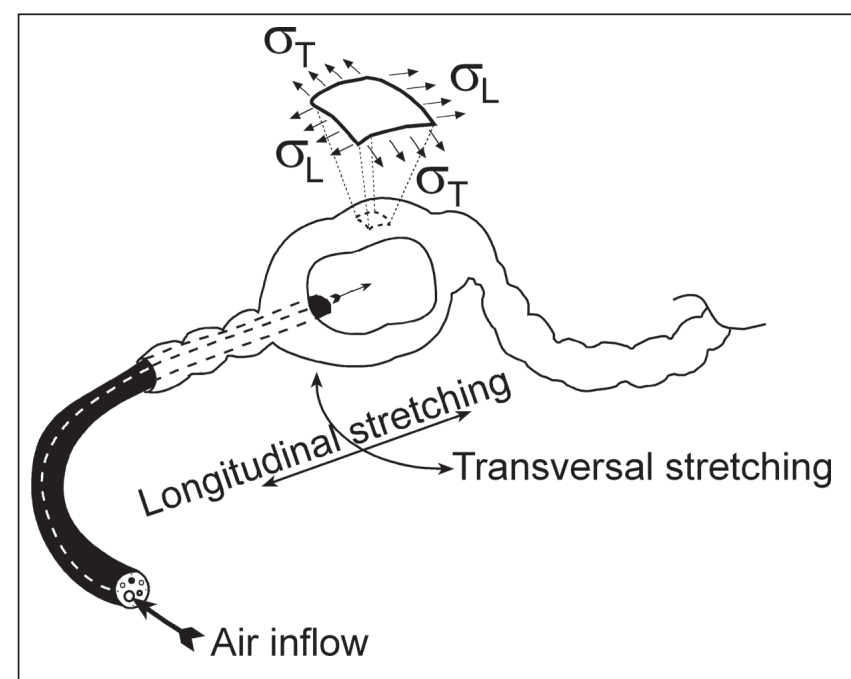

Figure 8) Longitudinal and transversal stretching of the colon wall and the stresses ( $\sigma$, with subscripts ' $L$ ' and ' $T$ ' for longitudinal and transverse stresses, respectively) resulting from inflation of the colon

little force on the wall of the transverse colon due to the usually large bending radius that is present in the transverse colon. Therefore, little stretching of the colon wall is required to balance the force exerted by the scope. However, in very long transverse colons (often in women) $(27,28)$ deep transverse looping $(1,2)$ can occur. This can complicate insertion due to: an acute bend halfway through the transverse colon, which increases the force required to bend the scope; and the long length of inserted scope shaft, which increases the risk of recurrent looping due to buckling. The mechanical causes are the relatively high stiffness of the scope (requiring greater resistance to bend the scope) and the lack of constraints on the long transverse colon.

The hepatic flexure is a mirror image of the splenic flexure. The proximal end of the hepatic flexure cannot adapt itself to the scope, making acute bending of the scope necessary. The unavoidable acute bend in the hepatic flexure increases the force required to bend and advance the scope. This required level of force, combined with the long preceding trajectory, increases the risk of recurrent looping. The straight and fixed ascending colon usually does not add difficulty, provided no recurrent looping is present $(1,2)$.

\section{Pain}

An empty colon is crumpled. If gas or feces accumulate, the colon can stretch like a balloon in the transverse and longitudinal directions, which can be painful $(29,30)$. The same occurs when the colon is inflated with air or carbon dioxide (which reduces postprocedural pain compared with air $[31,32]$ ) during colonoscopy to obtain proper viewing space and freedom of movement (Figure 8). The colon is fairly elastic; its maximum elongation before breakage has been measured to be up to $361 \%$ after necropsy (33). However, excessive stretching thins and tenses the colon wall and, thus, increases the risk of colon wall perforation (34).

It is clear that with conventional colonoscopy, some sigmoid looping or stretching is virtually unavoidable. It is not clear whether the sigmoid colon is stretched beyond its natural unfolded length or just unfolded during looping. Bhatnagar et al (35) measured the mean ( \pm SD) length of the unfolded sigmoid colon in live subjects in North India to be $44.4 \pm 9.6 \mathrm{~cm}$ in females and $48.6 \pm 12.4 \mathrm{~cm}$ in males. Saunders et al (36) measured the median of the unfolded length of rectum plus sigmoid colon in Western and Oriental live subjects to be $34 \mathrm{~cm}$ (range $17 \mathrm{~cm}$ to $78 \mathrm{~cm}$ ) and $33 \mathrm{~cm}$ (range $15 \mathrm{~cm}$ to $55 \mathrm{~cm}$ ), respectively. The rectum and the descending colon lie approximately $20 \mathrm{~cm}$ apart. If a sigmoid colon of $50 \mathrm{~cm}$ unfolded length (which is relatively long) is attached between rectum and descending colon and an $\alpha$-loop as large 


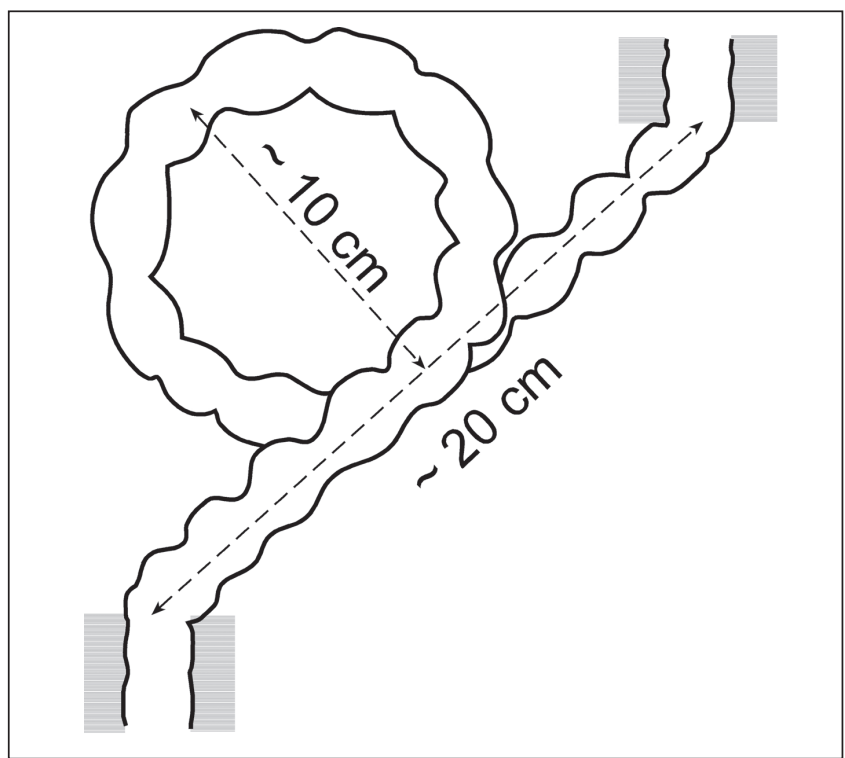

Figure 9) The sigmoid colon when not stretched beyond its unfolded length, looped between its two attachment points

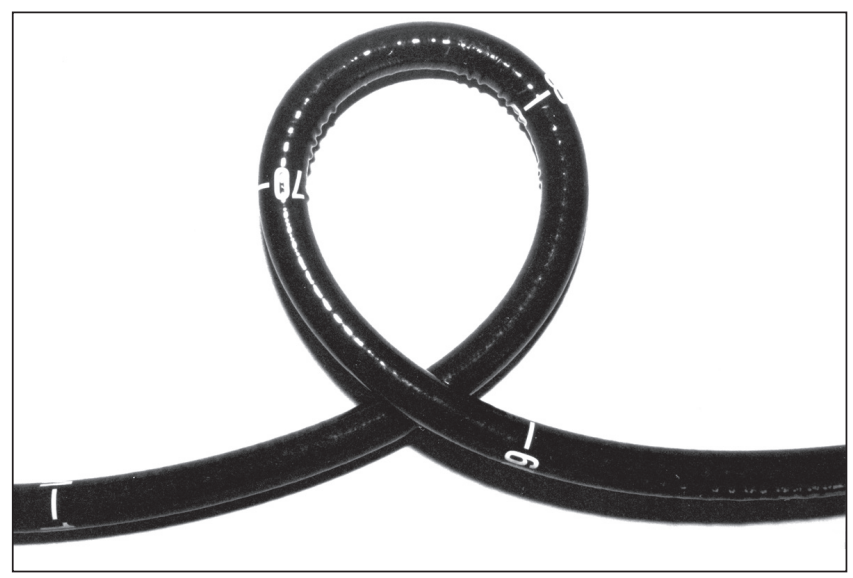

Figure 10) Olympus CF Type 130 colonoscope (Olympus, Japan) pulled to form an $\alpha$-loop. The loop diameter is approximately $10 \mathrm{~cm}$

as possible is formed in it without stretching the colon beyond its natural unfolded length, the loop resembles a $10 \mathrm{~cm}$ diameter circle lying on a $20 \mathrm{~cm}$ straight line (Figure 9).

To test whether such a loop can be adopted by a conventional scope, an Olympus CF Type 130 (Olympus, Japan) was forced into a minimal-diameter loop. The loop was made as small as possible by pulling at both ends of the shaft without damaging the scope. The resulting loop had a diameter of approximately $10 \mathrm{~cm}$ (Figure 10), which just fits the loop shown in Figure 9. However, it requires considerable force to obtain such a small loop and the colon will thus be substantially stretched beyond its natural unfolded length if the scope is advanced through such a loop. Because most sigmoid colons are shorter than $50 \mathrm{~cm}$ when unfolded, one can assume that some longitudinal stretching of the colon wall will occur during formation of loops or large bends. If longitudinal colon stretching causes pain, some level of pain during conventional colonoscopy without sedation will likely occur (16).

Because the colon is attached to the peritoneum, the peritoneum moves whenever the colon is moved or deformed. Because the peritoneum lies in large folds, it may be moved but also may be stretched (the mesenteries in particular) during movement or deformation of the colon.

When the scope is pushed through a bend, the bend stretches. However, if the colon were simply unconstrained, it would just translate

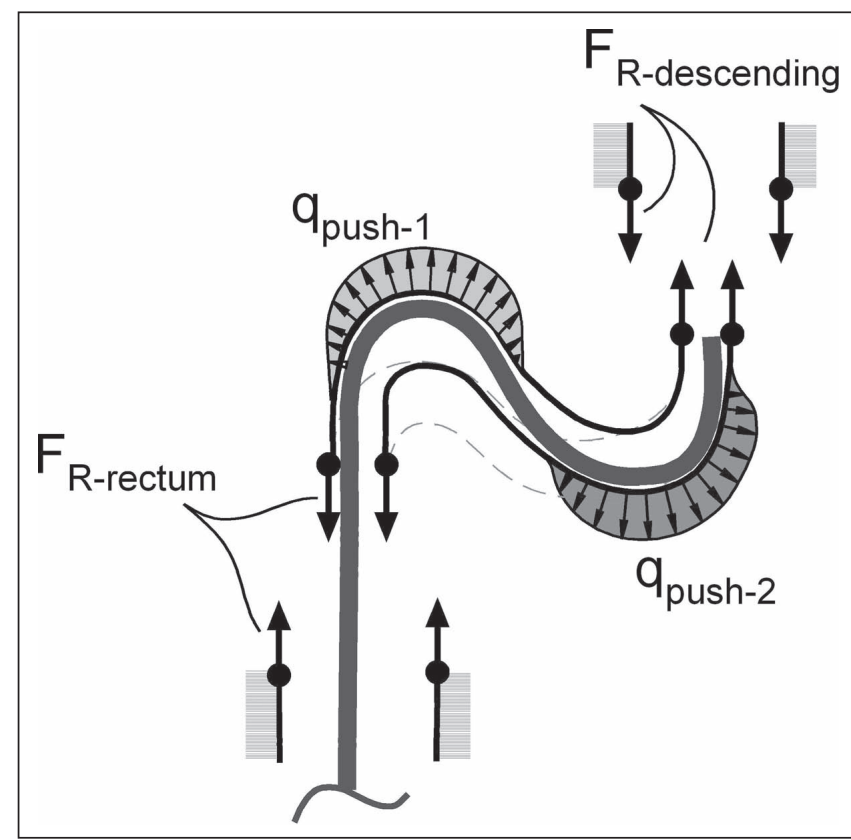

Figure 11) Free-body diagram of the modelled sigmoid colon showing constraining forces $\left(F_{R \text {-rectum }}\right.$ and $\left.F_{R \text {-descending }}\right)$ that act in the ligaments of the colon

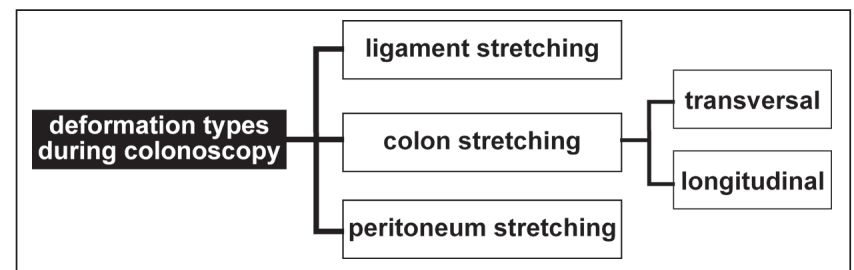

Figure 12) The four deformation types that are likely to occur during conventional colonoscopy

when pushed against instead of deforming and guiding the scope. It is evident that constraining reaction forces must be acting at the fixation points of the colon (Figure 11). Consequently, ligaments are being pulled and stretched during scope advancement. Little is known about the sensitivity of these ligaments to pain. However, the ligaments suspending the flexures and fixing the colon are comprised of peritoneal folds. Because the peritoneum is sensitive to traction and scratching, the same is also expected of these ligaments (30).

\section{RESULTS}

Fundamental mechanical causes

The considerations described above led to the conclusion that four deformation types occur during scope insertion (Figure 12). Which of these is most painful depends on the sensitivity of the colon, peritoneum and ligaments to stretching. There are several reports on pain during colonoscopy, but none clearly distinguishes the anatomical and physiological origins of the pain $(1,10,15-17,29,30,37)$. The overview of deformation types in Figure 12 can be used to systematically investigate the relationships between deformation types and pain. Being aware of these relationships may help to prevent these pain-causing deformations and reduce the use of sedatives.

Pain levels also depend on the amount of force applied to the colon wall and on the resulting strain in the colon wall. Forces exerted by the endoscopist's hand on the scope shaft are known to demonstrate peak forces (up to $3 \mathrm{~kg}$ push) that correspond with insertion difficulties, especially at the flexures and during looping $(23,38)$. Measurement of forces exerted directly on the colon wall in a Hoken colon model performed with a force-sensing sheet on the scope shaft - indicated a 


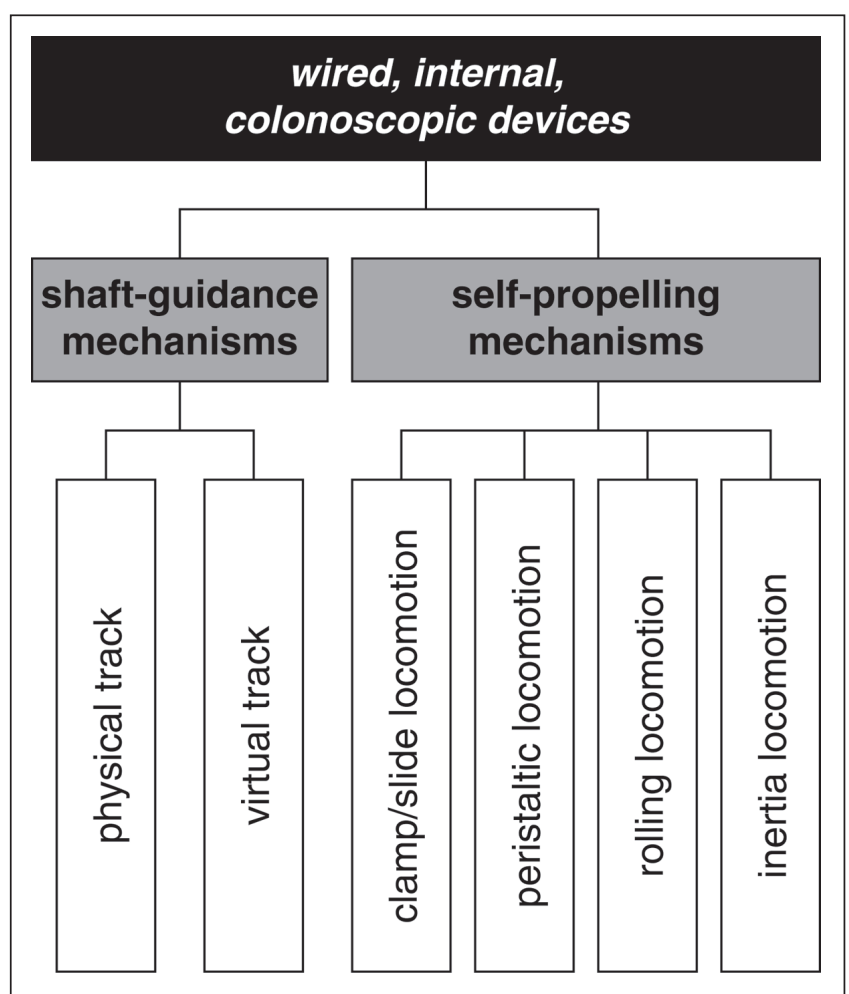

Figure 13) Categories of wired, internal colonoscopic devices that are potential alternatives to conventional colonoscopes

correlation between peak forces (up to approximately $1.3 \mathrm{~kg}$ push) exerted on the colon wall and insertion difficulties (39). Because difficult colonoscopy and pain are correlated $(10,16)$, it is likely that peak forces and pain are also correlated. However, to date, there are no conclusive data regarding force distributions or deformation types during scope insertion or about relationships between deformation types (Figure 12) and pain.

\section{SOLUTION DIRECTIONS}

All colonoscopy difficulties evidently arise from the need to advance the scope shaft by pushing while the colon is too lax to resist and redirect these forces. Preventing the four deformation types described would help prevent the discussed insertion difficulties and causes of pain. The forgoing analysis suggests four fundamental, mechanical solution directions:

- minimize inflation;

- make the scope follow the colonic bends more easily;

- make the colon provide better guidance to the scope; and

- prevent excessive pushing against the colon wall.

In conventional colonoscopy, transverse stretching of the colon can be limited by reducing inflation. Longitudinal colon stretching is unavoidable because pushing against the colon wall (which also causes stretching of the ligaments and the peritoneum) is unavoidable due to the (necessary) stiffness of the scope shaft. However, all stretching types may be limited by carefully choosing the correct scope manoeuvres in all situations, as described in colonoscopy manuals (eg, frequently pulling back the scope while advancing it through the sigmoid colon and straightening bends before further advancement) $(1,2)$. However, the endoscopist cannot visualize scope shaft behaviour and must operate on personal expertise or use some visualization method to decide which manoeuvres should be used and when. Due to this limitation, endoscopists misdiagnose $69 \%$ of loops, and applied ancillary techniques, such as applying hand pressure on the patient's belly or changing the patient's position, are only effective in $52 \%$ of attempts (40).
There are two methods to visualize the location and pose of a scope shaft in the colon: fluoroscopy and endoscope imaging systems such as the Olympus 'ScopeGuide' system $(1,2,16)$. However, the former carries the risk of radiation and does not appear to be acceptable except in highly selected cases. There are varying opinions about the results of endoscope imaging systems in the literature. It appears that loops are better handled by less experienced endoscopists; however, pain is not decreased (16,41-45).

\section{'FUTUROSCOPY'}

There are useful proposals for alternatives to colonoscopy with a regular scope (eg, a barium enema, three-dimensional computed tomography or magnetic resonance imaging, intestinal inspection with a camera pill) $(1,2,46-55)$. However, these still lack functionalities for therapeutic procedures (eg, removing polyps) and cannot replace the scopes currently in use.

Devices with a tube that extends out of the patient's body offer more possibilities than external visualization methods or wireless devices and are safer because if the device fails, the tube acts as a livewire so that the device can be pulled out. The tube also eliminates the necessity of equipping a tiny device with a power supply, light source, and air and water tanks.

A search for wired devices to be inserted into the anus that comply, at least in part, with the four suggested solution directions was conducted in the scientific and patent literature to find alternatives to conventional colonoscopes. The literature and patents were searched up to August 2011 using Scopus.com, Espacenet.nl and Freepatentsonline.com. Relevant key words and patent classes were used as search parameters. The results are categorized in Figure 13 and briefly discussed below with some examples.

Physical track shaft-guidance mechanisms are devices that physically guide the scope, similar to rails guiding a train (56). They are usually designed as overtubes (57-66). After negotiating the scope through some of the bends of the colon, a relatively stiff or selectively stiffened over-tube, such as the ShapeLock (USGI Medical, USA) overtube concept $(62,63,67)$, is slid over the scope shaft to prevent recurrent looping. Friedland and Soetikno (64) showed how a single stiffness overtube combined with a thin scope applies two of the suggested solution directions. After passing and straightening the sigmoid colon with the thin scope ("make the scope follow the colonic bends more easily") the overtube was introduced over the scope shaft. The overtube increases the scope's stiffness to prevent it from buckling during further advancement ("prevent the scope from excessive pushing against the colon wall"). However, it remains necessary to first negotiate through the convoluted colonic curves.

By combining two selectively stiffened overtubes, a system is obtained that should, in theory, be able to virtually prevent any stretching of the colon wall (except stretching due to excessive inflation) $(56,68,69)$. Unfortunately, to date, no such system has been demonstrated in the literature as a fully functional colonoscopy device.

Virtual track shaft-guidance mechanisms are devices that obtain trajectory shape information from the angulation of the scope tip and use that information to actively control the pose of the scope shaft during advancement to make the entire scope shaft follow the path of the scope tip in a snakelike manner (56). The oldest virtual track shaft-guidance mechanism found (70) contains a train of articulated segments with magnetic clutches that control the angulation of each segment (Figure 14). This design basically applies the same solution directions as physical track shaft-guidance mechanisms; however, similar to newer variants such as the NeoGuide system (NeoGuide Systems, USA), which was successfully demonstrated in the literature but was never made commercially available, may be very expensive due to its numerous parts $(71-76)$.

Self-propelling endoscopes are aimed at the solutions 'make the scope follow the colonic bends more easily' and 'prevent the scope from excessive pushing against the colon wall' by replacing the push forces acting on the scope shaft with a driving force applied directly at the tip. 


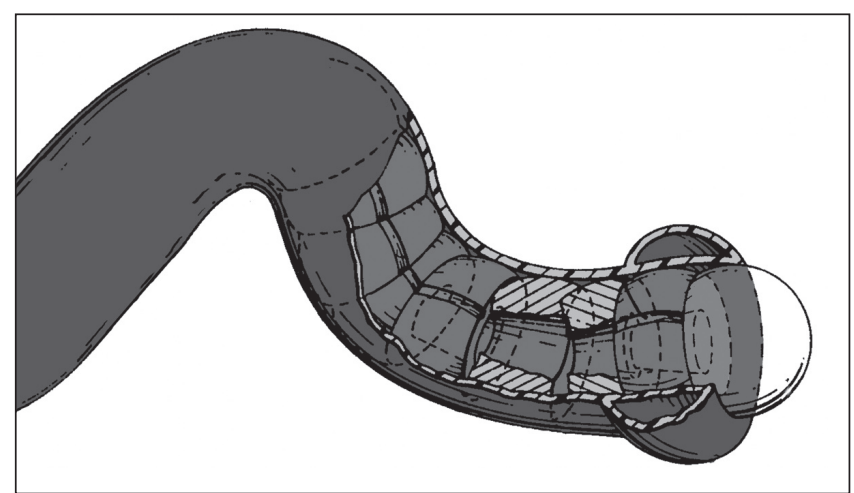

Figure 14) The distal end of an endoscope with a virtual track shaft-guidance mechanism. Inside a train of nested elements is shown, each element carries electromagnets to control the angulation of the element. Adapted from reference 70

Self-propelling endoscopes with clamp-slide mechanisms use contact and anchoring forces that are usually applied to the colon wall to anchor one part of the device while moving another part forward with respect to the anchored part. Such devices move like an inchworm or as a type of telescoping shaft. Although relatively simple, these devices are often slow, cannot anchor properly in the slippery colon, and may inflict pain or damage the colon because of their anchoring methods (34,52,77-87). Double-balloon colonoscopy (also known as double-balloon endoscopy) is an example of a successfully applied clamp-slide mechanism. Although it is time consuming, double-balloon colonoscopy can sometimes help to complete previously incomplete colonoscopies (88-91). The Sightline ColonoSight system (Stryker GI, USA) $(92,93)$ has an inelastic sleeve that is folded at the tip of the scope, extends over the scope shaft and is fixed outside the patient. Its scope tip is propelled by inflating the inelastic sleeve. The Aeroscope (GI View, Israel) (94) works similarly but is purely diagnostic and anchors in the rectum.

By actively controlling peristalsis of the colon, a device could be advanced by peristaltic locomotion without losing control of its movements, which is a limitation of existing camera pills. The devices described by Mosse et al $(95,96)$ (Figure 15) and Long et al $(97,98)$ are made to induce peristalsis by locally applying electrical pulses to the colon, which contracts where the pulse is applied. Such a device would apply all four solution directions at once. However, although experiments investigating controlled peristaltic locomotion in animals were reported (99-101), reports of successful locomotion of colonoscopy devices through controlled peristalsis could not be found.

Without slip, rolling through the colon could provide fast and continuous locomotion. Breedveld et al (102) designed a colonoscopy device that uses rolling locomotion (Figure 16). It uses doughnutshaped constructions of metal gauze stents to propel the device. The stents are driven by cables and mounted around an endoscope. Although seemingly feasible, no literature was found about tests with this or other rolling systems $(52,103-105)$. Ongoing research on mucoadhesive materials $(106,107)$ is aimed at obtaining grip in the colon by sticking to the mucosa. These materials can be used to increase grip in the colon for rolling and clamp-slide locomotion.

Inertia locomotion mechanisms use the inertia of masses to generate propulsion forces. Two types of inertia locomotion were found: jet propulsion $(108,109)$ and propulsion by impact of a mass inside the endoscope $(110,111)$. Jet propulsion mechanisms accelerate water jets that are aimed backward from the endoscope tip to generate a reaction force on the endoscope tip for propulsion. In mass-impact mechanisms, a mass that can move inside the endoscope tip is launched against the front of the endoscope tip to transfer momentum. No data on tests with such mechanisms were found.

Some adaptations of current colonoscopes have been suggested that are elegant and helpful but tackle the problems less rigorously and are, therefore, not included in Figure $13(14,65,112-114)$. For example,

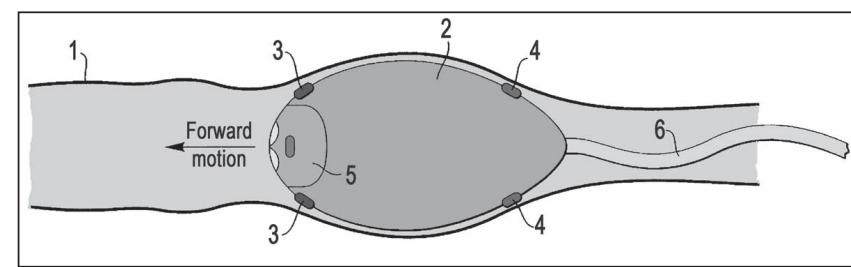

Figure 15) A self-propelling endoscopic device that uses induced peristalsis. (Numbered parts: 1 Colon; 2 Device body; 3 Electrodes for colon stimulation for backward motion; 4 Electrodes for colon stimulation for forward motion; 5 Exit hole; 6 Flexible tube with channels for instruments, air and electronic wiring.) Adapted from reference 95

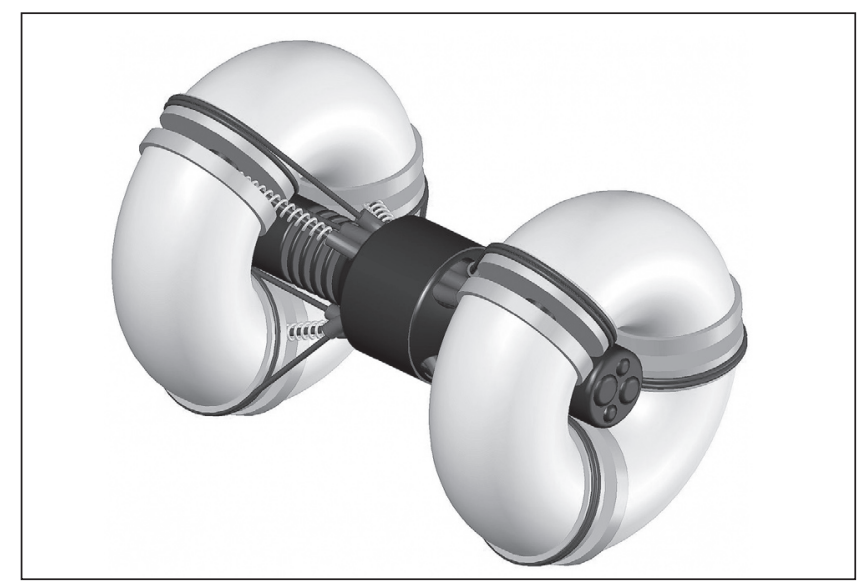

Figure 16) An endoscopic device propelled by doughnut-shaped constructs of metal gauze stents. Adapted from reference 102

Saito and Kimura (115) adapted a conventional colonoscope by adding an extra flexible section in the scope shaft proximal to the tip. This extra flexible section helps in passing difficult bends by reducing the forces that are applied to the colon wall by the tip. This elegant solution facilitates pushing the tip past sharp bends, but still does not prevent force being applied to the colon wall after the tip has passed the bend.

Overall, many suggestions for better colonoscopy devices have been proposed, but none appear to be sufficiently developed to offer a complete solution. Providing a device that fully complies with all four suggested solution directions - to eliminate the current need for highly skill-dependent scope manoeuvres and sedatives - continues to be an important next step for clinicians and medical engineers.

\section{CONCLUSIONS}

The fundamental mechanical causes of insertion problems and pain during conventional colonoscopy were identified using a mechanical analysis of colonoscopy performed without the application of conventional, highly skill-dependent manoeuvres. The four basic deformation mechanisms of the colon and its surroundings that occur during colonoscope insertion were described: ligament stretching, transverse and longitudinal stretching of the colon, and stretching of the peritoneum. Which deformation type occurs most often or is most painful remains unknown. Following the problem analysis, four fundamental, mechanical solution directions were suggested: minimize inflation, make the scope follow colonic bends more easily, make the colon provide better guidance to the scope and prevent excessive pushing against the colon wall. A categorization of concepts for alternatives to colonoscopes currently in use suggested that the need for a colonoscopy device that implements all four suggested solution directions has not yet been met. A device that fully prevents all stretching types, and thus all related pain causes, should be made available. Such a device would greatly simplify the insertion of a colon inspection device and could reduce colonoscopy complications, training needs, training costs and the need for sedatives. 
ACKNOWLEDGEMENTS: The authors thank Dr Gert-Jan Kleinrensink of the Erasmus Medical Center for arranging the opportunity to extensively study the anatomy of the colon and its attachments in human cadavers.

DISCLOSURES: The authors have no financial disclosures or conflicts of interest to declare.

\section{REFERENCES}

1. Classen M, Tytgat GNJ, Lightdale CJ. Gastroenterological Endoscopy. Stuttgart: Thieme Medical Publishers; 2002.

2. Waye JD, Rex DK, Williams CB. Colonoscopy: Principles and Practice. Oxford: Blackwell Publishing; 2003.

3. Ball JE, Osbourne J, Jowett S, Pellen M, Welfare MR. Quality improvement programme to achieve acceptable colonoscopy completion rates: Prospective before and after study. BMJ 2004;329:665-7.

4. Cotton PB, Connor P, McGee D, et al. Colonoscopy: Practice variation among 69 hospital-based endoscopists. Gastrointest Endosc 2003;57:352-7.

5. Gorard DA, McIntyre AS. Completion rate to caecum as a quality measure of colonoscopy in a district general hospital. Colorectal Dis 2004;6:243-9.

6. Lee SH, Chung IK, Kim SJ, et al. An adequate level of training for technical competence in screening and diagnostic colonoscopy: A prospective multicenter evaluation of the learning curve. Gastrointest Endosc 2008;67:7.

7. Rex DK, Bond JH, Winawer S, et al. Quality in the technical performance of colonoscopy and the continuous quality improvement process for colonoscopy: Recommendations of the U.S. Multi-Society Task Force on Colorectal Cancer. Am J Gastroenterol 2002;97:1296-308.

8. Bowles CJA, Leicester R, Romaya C, Swarbrick E, Williams CB, Epstein O. A prospective study of colonoscopy practice in the UK today: Are we adequately prepared for national colorectal cancer screening tomorrow? Gut 2004;53:277-83.

9. Harewood GC. Colonoscopy: Not quite the gold standard. Dig Liver Dis 2007;39:690-1.

10. Hull T, Church JM. Colonoscopy - how difficult, how painful? Surg Endosc 1994;8:784-7.

11. Depew WT, Hookey LC, Vanner SJ, et al. Opportunity costs of gastrointestinal endoscopic training in Canada. Can J Gastroenterol 2010;24:733-8.

12. Petrini JL, Egan JV, Hahn WV. Unsedated colonoscopy: Patient characteristics and satisfaction in a community-based endoscopy unit. Gastrointest Endosc 2009;69:567-72.

13. Porostocky P, Chiba N, Colacino P, Sadowski D, Singh H. A survey of sedation practices for colonoscopy in Canada. Can J Gastroenterol 2011;25:255-60.

14. Leung FW. Methods of reducing discomfort during colonoscopy. Dig Dis Sci 2008;53:1462-7.

15. Mitchell RM, McCallion K, Gardiner KR, Watson RG, Collins JS. Successful colonoscopy; completion rates and reasons for incompletion. Ulster Med J 2002;71:7.

16. Shah SG, Brooker JC, Thapar C, Williams CB, Saunders BP. Patient pain during colonoscopy: An analysis using real-time magnetic endoscope imaging. Endoscopy 2002;34:435-40.

17. Waye JD. The most important maneuver during colonoscopy. Am J Gastroenterol 2004;99:2086-7.

18. Coderre S, Anderson J, Rikers R, Dunckley P, Holbrook K, McLaughlin K. Early use of magnetic endoscopic imaging by novice colonoscopists: Improved performance without increase in workload. Can J Gastroenterol 2010;24:727-32.

19. Mohamed R, Shaheen AA, Raman M. Evaluation of colonoscopy skills - how well are we doing? Can J Gastroenterol 2011;25:198-200.

20. Waye JD, Bashkoff E. Total colonoscopy: Is it always possible? Gastrointest Endosc 1991;37:152-4.

21. Waye JD. The best way to painless colonoscopy. Endoscopy 2002;34:489-91.

22. Webb WA. Colonoscoping the 'difficult' colon. Am Surg 1991;57:178-82.

23. Mosse C, Mills T, Bell G, Swain C. Device for measuring the forces exerted on the shaft of an endoscope during colonoscopy. Med Biol Eng Comp 1998;36:186-90.
24. Pottecher T, Segura P, Launoy A. [Le syndrome du compartiment abdominal.] [French]. Ann Chir 2001;123:9.

25. Rozov R, Pottecher T, Launoy A. [Mesure de la pression intraabdominale par voie vesicale.] [French]. Ann Fr Anesth Reanim 2004;23:433-4.

26. Nathens AB, Brenneman FD, Boulanger BR. The abdominal compartment syndrome. Can J Surg 1997;40:5.

27. Rowland R, Bell G, Dogramadzi S, Allen C. Colonoscopy aided by magnetic 3D imaging: Is the technique sufficiently sensitive to detect differences between men and women? Med Biol Eng Comp 1999;37:673-9.

28. Saunders BP, Fukumoto M, Halligan $\mathrm{S}$ et al. Why is colonoscopy more difficult in women? Gastrointest Endosc 1996;43:124-6.

29. Bassotti G, Gaburri M, Imbimbo BP, Morelli A, Whitehead WE. Distension-stimulated propagated contractions in human colon. Dig Dis Sci 1994;39:1955-60.

30. Clinton Texter E. Digestive tract pain. Dig Dis Sci 1958;3:877-900.

31. Bretthauer M, Lynge AB, Thiis-Evensen E, Hoff G, Fausa O, Aabakken L. Carbon dioxide insufflation in colonoscopy: Safe and effective in sedated patients. Endoscopy 2005;37:706-9.

32. Church J, Delaney C. Randomized, controlled trial of carbon dioxide insufflation during colonoscopy. Dis Colon Rectum 2003:46:322-6.

33. Watters DAK, Smith AN. Strength of the colon wall in diverticular disease. Br J Surg 1990;77:257-9.

34. Schwarzman M, Attiyeh F. Self-inflicted sigmoid colon perforation. Dis Colon Rectum 1984;27:199-202.

35. Bhatnagar BNS, Sharma CLN, Gupta SN, Mathur MM, Reddy DCS. Study on the anatomical dimensions of the human sigmoid colon. Clin Anat 2004;17:236-43.

36. Saunders BP, Masaki T, Sawada T, et al. A peroperative comparison of Western and Oriental colonic anatomy and mesenteric attachments. Int J Colorectal Dis 1995;10:216-21.

37. Marieb EN. Human Anatomy \& Physiology, 6th edn. San Francisco: Benjamin Cummings; 2004.

38. Appleyard MN, Mosse CA, Mills TN, Bell GD, Castillo FD, Swain CP. The measurement of forces exerted during colonoscopy. Gastrointest Endosc 2000;52:237-40.

39. Dogramadzi S, Virk GS, Bell GD, Rowland RS, Hancock J. Recording forces exerted on the bowel wall during colonoscopy: In vitro evaluation. Int J Med Rob Com Ass Surg 2005;1:9.

40. Shah SG, Saunders BP, Brooker JC, Williams CB. Magnetic imaging of colonoscopy: An audit of looping, accuracy and ancillary maneuvers. Gastrointest Endosc 2000;52:1-8.

41. Shah SG, Brooker JC, Williams CB, Thapar C, Saunders BP. Effect of magnetic endoscope imaging on colonoscopy performance: A randomised controlled trial. Lancet 2000;356:1718-22.

42. Shah SG, Thomas-Gibson S, Lockett M, et al. Effect of real-time magnetic endoscope imaging on the teaching and acquisition of colonoscopy skills: Results from a single trainee. Endoscopy 2003;35:421-5.

43. von Delius S, Feussner H, Schmid RM, Frimberger E. [Was bringt die elektromagnetische Navigation bei der Routine-Koloskopie?] [German with English abstract]. Endoskopie Heute 2006;19:3.

44. Shah SG, Brooker JC, Thapar C, Suzuki N, Williams CB, Saunders BP. Effect of magnetic endoscope imaging on patient tolerance and sedation requirements during colonoscopy: A randomized controlled trial. Gastrointest Endosc 2002;55:832-7.

45. Ambardar S, Arnell TD, Whelan RL, Nihalani A, Forde KA. A preliminary prospective study of the usefulness of a magnetic endoscope locating device during colonoscopy. Surg Endosc 2005;19:897-901.

46. Appleyard M, Fireman Z, Glukhovsky A, et al. A randomized trial comparing wireless capsule endoscopy with push enteroscopy for the detection of small-bowel lesions. Gastroenterol 2000;119:1431-8.

47. Brown GJE, Saunders BP. Advances in colonic imaging: Technical improvements in colonoscopy. Eur J Gastroenterol Hepatol 2005; 17:785-92.

48. Ell C, Remke S, May A, Helou L, Henrich R, Mayer G. The first prospective controlled trial comparing wireless capsule endoscopy with push enteroscopy in chronic gastrointestinal bleeding. Endoscopy 2002:685-9.

49. Kim B, Lim HY, Park JH, Park J-O. Inchworm-like colonoscopic robot with hollow body and steering device. JSME Int J 2006;49:8.

50. Luboldt W, Debatin JF. Virtual endoscopic colonography based on 3D MRI. Abdom Imaging 1998;23:568-72. 
51. Scheidler J, Frank C, Becker C et al. [Virtuelle CT- und MRTKoloskopie.] Der Radiologe 1998;38:824-31.

52. Kim B, Lim YM, Lee YJ, Hong Y-S, Kim SH, Park J-O, inventors; Micro Robot for Colonoscope with Motor Locomotion and System for Colonoscope Using the Same. Korea patent 6,648,814. November 18, 2003.

53. Lichan H, Kaufman A, Yi-Chih W, Viswambharan A, Wax M, Zhengrong L. 3D virtual colonoscopy. In: Loew M, Gershon N, eds. Biomedical Visualization, 1995. Proceedings; October 30 to November 3; Atlanta. Piscataway: IEE;1995:26-32,83.

54. Adler DG, Chand B, Conway JD, et al. Capsule endoscopy of the colon. Gastrointest Endosc 2008;68:621-3.

55. Triantafyllou K, Tsibouris P, Kalantzis C et al. PillCam colon capsule endoscopy does not always complement incomplete colonoscopy. Gastrointest Endosc 2009;69:572-6.

56. Loeve AJ, Breedveld P, Dankelman J. Scopes too flexible...and too stiff. IEEE Pulse 2010;1:26-41.

57. Bauerfeind $P$, Bauerfeind $H$, inventors; Tubular Inserting Device with Variable Rigidity. Germany patent 5,337,733. August 16, 1994.

58. Butler J, Bonadio F, Park JH, inventors; Colonic Overtube. US patent 6,793,621. September 21, 2004.

59. Ewers RC, Vahid S, Chen EG, inventors; Shape Lockable Apparatus and Method for Advancing an Instrument Through Unsupported Anatomy. US patent 6,837,847. January 4, 2005.

60. Saadat V, Ewers RC, Chen EG, inventors; Shape lockable apparatus and method for advancing an instrument through unsupported anatomy. US Patent $(6,790,173$ B2) patent 6,790,173. September 14, 2004.

61. Tartaglia JM, Keller WA, Belson A, Ratchford AR, inventors; NeoGuide Systems, Inc., assignee. Endoscope with adjacently positioned guiding apparatus. US patent 6,984,203. January 10, 2006.

62. Rex DK, Khashab M, Raju GS, Pasricha J, Kozarek R. Insertability and safety of a shape-locking device for colonoscopy. Am J Gastroenterol 2005;100:4.

63. Raju GS, Rex DK, Kozarek RA, Ahmed I, Brining D, Pasricha PJ. A novel shape-locking guide for prevention of sigmoid looping during colonoscopy. Gastrointest Endosc 2004;59:416-9.

64. Friedland S, Soetikno RM. Small caliber overtube-assisted colonoscopy. World J Gastroenterol 2007;13:5933-7.

65. Fritscher-Ravens A, Fox S, Swain CP, Milla P, Long G. CathCam guide wire-directed colonoscopy: First pilot study in patients with a previous incomplete colonoscopy. Endoscopy. 2006;38:209-13.

66. Garcia P, Low T, Chavez B, Prahlad H, Isaza N, Dutta S, inventors; SRI International and The Board of Trustees of the Leland Stanford Junior University, assignee. Controllable dexterous endoscopic device. US patent 2009/0030282. January 29, 2009.

67. Saadat V, Ewers RC, Chen EG, Miller D, inventors; USGI Medical, Inc, assignee. Endoluminal tool deployment system. US patent 7,918,845. April 5, 2011.

68. Zubiate B, Choset H, inventors; Cardiorobotics Inc, assignee. Extendable articulated probe device. US patent 2011/0184241. July 28, 2011.

69. Chen Y, Chang JH, Greenlee AS, et al, eds. Multi-turn, tension stiffening catheter navigation system. 2010 IEEE International Conference on Robotics and Automation (ICRA); May 3 to 7 , 2010; Anchorage, Alaska, USA.

70. Seufert WD, Bessette FM, inventors; Device for Carrying Observation and/or Manipulation Instruments. Canada patent 4,054,128. October 18, 1977.

71. Belson A, inventor, NeoGuide Systems, Inc, assignee. Methods and apparatus for performing transluminal and other procedures. US patent 2007/033379. March 22, 2007.

72. Ohline RM, Tartaglia JM, Belson A, inventors; Tendon-Driven Endoscope and Methods of Insertion. US patent 6,858,005. February 22, 2005.

73. Eickhoff A, Van Dam J, Jakobs R, et al. Computer-Assisted Colonoscopy (The NeoGuide Endoscopy System): Results of the First Human Clinical Trial ("PACE Study"). Am J Gastroenterol 2007;102:261-6.

74. Eickhoff A, Jakobs R, Kamal A, Mermash S, Riemann JF, van Dam J. In vitro evaluation of forces exerted by a new computer-assisted colonoscope (the NeoGuide Endoscopy System). Endoscopy 2006:1224-9.
75. Belson A, DeWitt FP, McElhaney CWH, Milroy JC, Ohline RM, Tartaglia JM, inventors; Steerable segmented endoscope and method of insertion. US patent 2011/0065993. March 17, 2010.

76. Couvillon LAJ, inventor, Boston Scientific Scimed Inc, assignee. Robotic endoscope. US patent 7,666,135. February 23, 2010.

77. Grundfest WS, Burdick JWI, Slatkin AB, inventors; Robotic Endoscopy. US patent 5,337,732. August 16, 1994.

78. Krasner JL, DiBenedetto JP, inventors. Medical apparatus having inflatable cuffs and a middle expandable section. US patent 4,676,228. June 30, 1987.

79. Lyddy JEJ, Penland WZ, Sugarbaker PH, inventors; Medical Apparatus. US patent 4,690,131. September 1, 1987.

80. Ortiz MS, Stubbs JB, inventors; Lumen Traversing Device. US patent 5,398,670. March 4, 1995.

81. Choy DSJ, inventor, Self-propelled conduit traversing device. US patent 3,895,637. July 22, 1975.

82. Chiel HJ, Quin RD, Beer RD, Mangan ED, inventors; Peristaltically Selfpropelled Endoscopic Device. US patent 6,764,441. July 20, 2004

83. Mangan EV, Kingsley DA, Quinn RD, Chiel HJ. Development of a peristaltic endoscope. IEEE International Conference on Robotics and Automation; May 11-15; Washington, D.C., USA. Piscataway, New Jersey, USA: IEEE; 2002.

84. Dario P, Carrozza MC, Lencioni L, Magnani B, D’Attanasio S. Micro robotic system for colonoscopy. IEEE International Conference on Robotics and Automation; April 20-25; Albuquerque, New Mexico, USA. Piscataway, NJ, USA: IEEE; 1997:1567-72.

85. Ng WS, Phee SJ, Seow C, Davies BL. Development of a robotic colonoscope. Dig Endosc 2000;12:131-5.

86. Bob K, Pauker F, Viebach T, inventors. Alternating propulsion type endoscope and continuous drive type endoscope. Germany patent 7,798,956. September 21, 2010.

87. Ewers RC, Reydel B, Chen EG, Saadat V, inventors; USGI Medical Inc, assignee. Apparatus and methods for achieving endoluminal access. US patent 7,955,253. June 7, 2011.

88. Byeon JS, Jung KW, Song HS, et al. A pilot study about tolerability to double balloon endoscopy: Comparison to esophagogastroduodenoscopy and colonoscopy. Dig Dis Sci 2008;54:2434-40.

89. Friedland S, Kaltenbach T, Soetikno R. Use of the double balloon enteroscope system to complete incomplete colonoscopy. Tech Gastrointest Endosc 2008;10:124-7.

90. Kaltenbach T, Soetikno R, Friedland S. Use of a double balloon enteroscope facilitates caecal intubation after incomplete colonoscopy with a standard colonoscope. Dig Liver Dis 2006;38:921-5.

91. Pasha SF, Harrison ME, Das A, Corrado CM, Arnell KN, Leighton JA. Utility of double-balloon colonoscopy for completion of colon examination after incomplete colonoscopy with conventional colonoscope. Gastrointest Endosc 2007;65:848-53.

92. Shike M, Fireman Z, Eliakim R, et al. Sightline ColonoSight system for a disposable, power-assisted, non-fiber-optic colonoscopy (with video). Gastrointest Endosc 2008;68:701-10.

93. Bar-Or J, Aizenfeld A, Golan S, inventors; SightLine Technologies, assignee. Endoscopic apparatus provided with inflatable propelling sleeve. US patent 2005/110204. November 24, 2005.

94. Vucelic B, Rex DK, Pulanic R, et al. The Aer-O-Scope: Proof of concept of a pneumatic, skill-independent, self-propelling, selfnavigating colonoscope. Gastroenterology 2006;130:672-7.

95. Mosse CA, Mills T, Swain P, inventors; Passage Travelling Device. US patent 6,709,388. March 23, 2004.

96. Mosse CA, Mills TN, Appleyard MN, Kadirkamanathan SS, Swain CP. Electrical stimulation for propelling endoscopes. Gastrointest Endosc 2001;54:79-83.

97. Long GL, Wales KS, inventors; Self-Propelled, Intraluminal Device with Working Channel and Method of Use. US patent 6,866,626. March 15, 2005.

98. Long GL, inventor, Ethicon Endo-Surgery Inc, assignee. Medical instrument having a catheter and method for using a catheter. US patent 7,597,661. October 6, 2009.

99. Park H-J, Lee J-H, Moon Y-K, et al. New method of moving control for wireless endoscopic capsule using electrical stimuli. IEICE Trans Fund 2005;E88-A(6):1476-80.

100. Sevcencu C, Rijkhoff NJM, Gregersen H, Sinkjaer T. Propulsive activity induced by sequential electrical stimulation in the descending colon of the pig. Neurogastroenterol Motil 2005;17:376-87. 
101. Moon Y, Lee J, Park H, et al. Fabrication of the wireless systems for controlling movements of the electrical stimulus capsule in the small intestines. IEICE Trans Info Syst. 2007;E90-D(2):586-93.

102. Breedveld P. Development of a Rolling Stent Endoscope. First IEEE/ RAS-EMBS International Conference on Biomedical Robotics and Biomechatronics. February 20 to 22, Pisa, Italy. Piscataway, New Jesrsey, USA:IEEE; 2006:921-6.

103. Takada M, inventor Self-propelled colonoscope. Japan patent 6,071,234. June 6, 2000.

104. Ziegler TJ, Sheridan TP, Ryder WT, inventors; Propulsion mechanism for endoscopic systems. US patent $6,971,990$. December 6, 2005.

105. Anhalt DJ, Herron JB, inventors; Science Application International Corporation, assignee. Toroidal propulsion and steering system. US patent 7,387,179. June 17, 2008.

106. Dodou D, Breedveld P, Wieringa PA. The role of geometry in the friction generated on the colonic surface by mucoadhesive films. J Appl Phys 2006;100(1)

107. Dodou D, Van Den Berg M, Van Gennip J, Breedveld P, Wieringa PA. Mucoadhesive films inside the colonic tube: Performance in a three-dimensional world. J R Soc Interf 2008;5:1353-62.
108. Shim HB, Cho WW, Hwang JJ, KIM KS, Seo YD, Kim EY, inventors; Intromedic. Co, Ltd, assignee. An endoscope and a method for moving it. Korea patent 2008/016196 A1.

February 7, 2008.

109. Swain CP, Mosse CA, Bell GD, Mills TN. Water jet propelled colonoscopy: A new method of endoscope propulsion. Gastrointest Endosc 1998;47:AB40.

110. Borody TJ, Stephenson P, Begg J, Ayre P, inventors; Self-Advancing Endoscope. US patent 6,332,865. December 25, 2001.

111. Soutorine M, Gulia N, Tchepikov I, inventors; Endogene PTY. LTD, assignee. Self-Advancing Device. Australia patent 03/053225. July 3, 2003.

112. Dickey W, Garrett D. Colonoscope length and procedure efficiency. Am J Gastroenterol 2002;97:79-82.

113. Eisen GM. Building a better colonoscope? Gastrointest Endosc 2008;68:711-2.

114. Ginsberg GG. Colonoscopy with the variable stiffness colonoscope. Gastrointest Endosc 2003;58:579-84.

115. Saito Y, Kimura H. Responsive insertion technology. Dig Endosc 2011;23:164-7. 


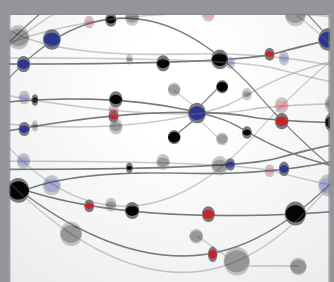

The Scientific World Journal
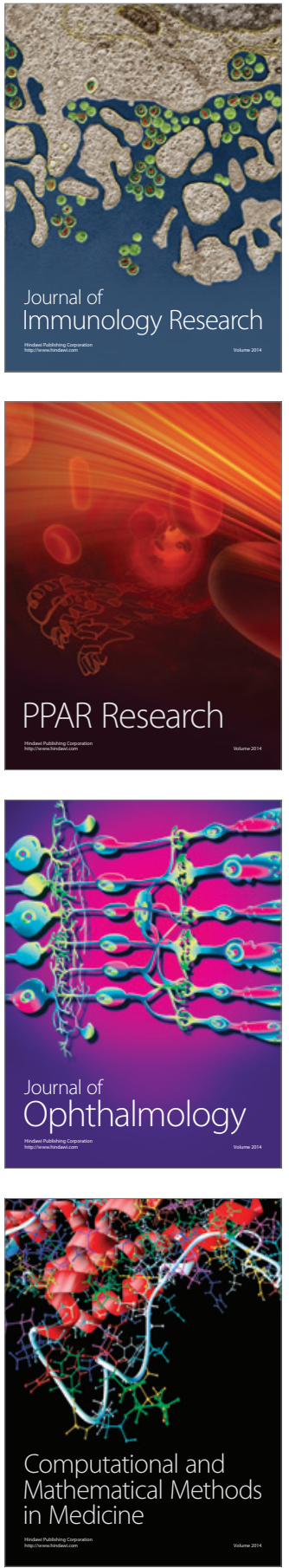

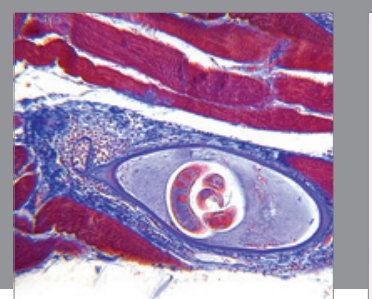

Gastroenterology Research and Practice

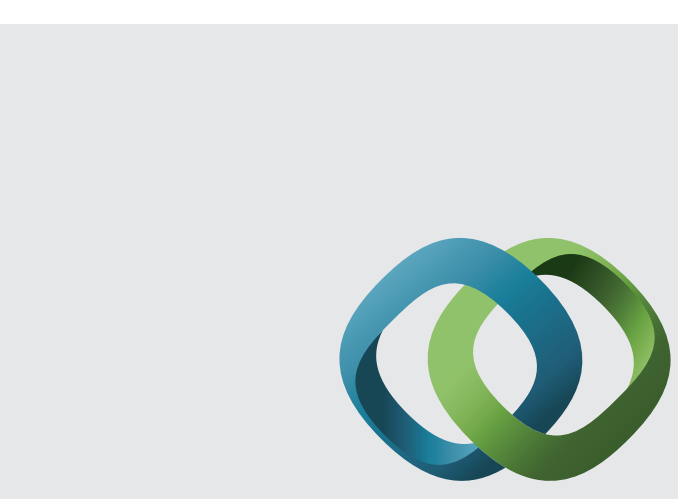

\section{Hindawi}

Submit your manuscripts at

http://www.hindawi.com
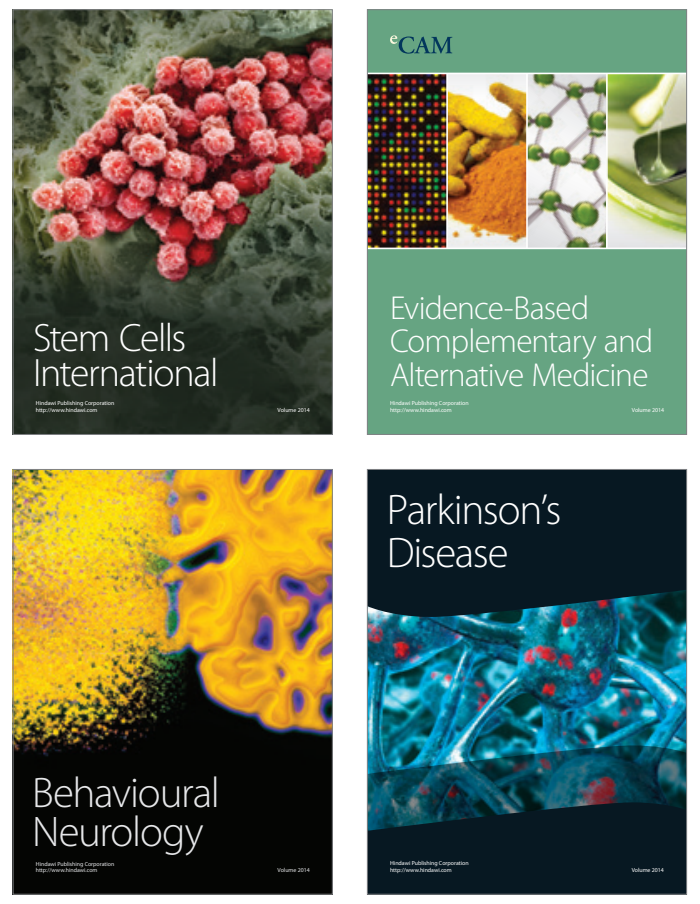
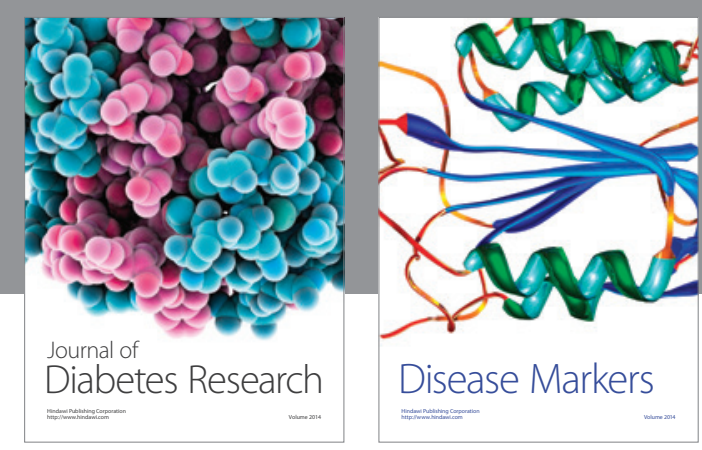

Disease Markers
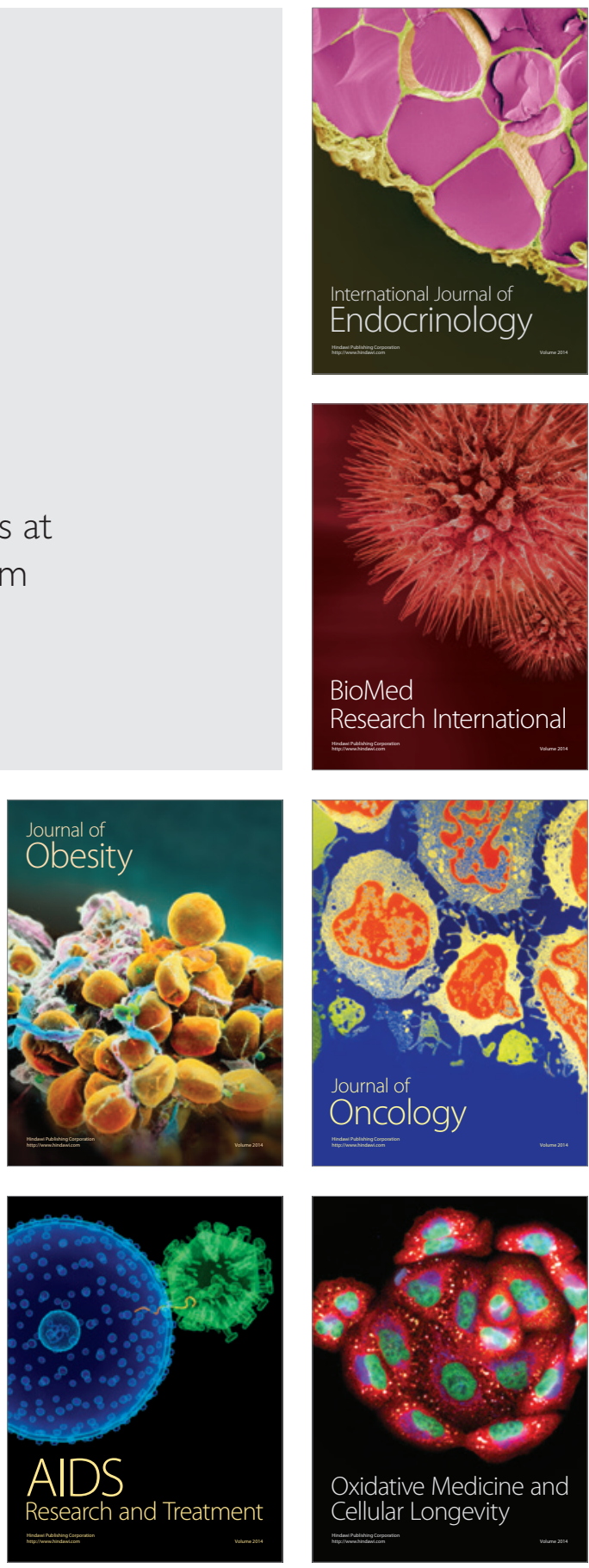